\title{
PENGEMBANGAN BAHAN AJAR BERBASIS ICT PADA MATA PELAJARAN
}

\section{IPA-KIMIA SMP}

\section{Maria Paristiowati, Irma Ratna K, Aftuni}

Jurusan Kimia, Fakultas Matematika dan IImu Pengetahuan Alam,Universitas Negeri Jakarta, Rawamangun 13220, Jakarta

*Corresponding author: maria@yahoo.com

\begin{abstract}
Abstrak
Pada penelitian ini dilakukan pengembangan bahan ajar berupa CD pembelajaran untuk kelas VII SMP dengan materi perubahan fisika dan kimia (reaksi kimia). Tahap-tahap dalam penelitian dan pengembangan yang telah dilakukan ini meliputi: (1) analisis kebutuhan, (2) tahap pengembangan produk, (3) tahap uji kelayakan dan uji coba. Analisis kebutuhan yang dilakukan terhadap siswa kelas VII SMPN 5 Bekasi sebanyak 39 responden dengan hasil, 100\% responden pernah menggunakan komputer dengan interval yang cukup sering (79,92\%). Lebih dari setengah responden $(66,67 \%)$ menyatakan bahwa materi IPA (kimia) kelas VII cukup sulit. Tahap pengembangan produk diawali dengan studi literatur untuk mendapatkan isi bahan ajar yang dibuat, pembuatan bahan ajar berupa CD interaktif. Bahan ajar dibuat dengan menggunakan fasilitas program macromedia Flash yang interaktif, berisikan animasi aplikasi reaksi kimia, proses terjadinya reaksi kimia, dan latihan soal yang berisikan evaluasi berupa soal pilihan ganda. Alokasi waktu isi CD pembelajaran ini berkisar antara 15 - 20 menit.

Tahap uji kelayakan oleh ahli materi, media dan guru memberikan hasil bahwa CD pembelajaran yang telah dikembangkan layak untuk digunakan. Sedangkan uji coba kelompok kecil dan besar dilakukan pada siswa kelas IX SMPN 5 Bekasi dan SMP Terpadu Widya Duta Bekasi memberikan hasil interpetrasi yang sangat baik sehingga dapat disimpulkan bahwa CD pembelajaran materi perubahan fisika dan kimia kayak digunakan.
\end{abstract}

Kata kunci: Bahan ajar berbasis/CT, Perubahan Fisika \& Kimia, Penelitian Pengembangan

\section{Pendahuluan}

Saat ini bahan ajar tertulis dalam bentuk buku seperti modul sudah banyak dibuat, namun bahan ajar yang ditampilkan dalam media audio visual berbasis ICT (Information Communication and Technology) belum banyak dikembangkan (Sudrajat, 2010). Visualisasi yang lebih nyata sangat mendukung pemahaman siswa dalam proses pembelajaran. Selain itu, siswa mendapatkan variasi dalam proses belajar mereka. Daya imajinasi siswapun akan bertambah yang pada akhirnya diharapkan akan mendorong munculnya kreativitas siswa. Peran dan kegunaan ICT dalam pembelajaran IPA pun dirasakan guru sangat bermanfaat (Juanda dkk, 2007).
Model multimedia atau hypermedia adalah penggabungan berbagai media, seperti teks, suara, gambar, animasi, atau video dalam satu software.

Penelitian Schade menyatakan bahwa pemanfaatan model multimedia dalam pembelajaran dapat meningkatkan daya ingat siswa 25-30\% (Munir, 2001).Selain itu, studi yang dilakukan di Amerika Serikat sangat mendukung.

Dikembangkannya pembelajaran menggunakan komputer, dan dinyatakan bahwa computer based learning sangat efektif, yang memungkinkan $30 \%$ pendidikan lebih baik, $40 \%$ waktu lebih singkat, dan $30 \%$ biaya lebih murah (Muslim, 2007). 
Kimia sebagai salah satu mata pelajaran di sekolah menengah, mempelajari konsep-konsep dan rumusrumus yang mendukung konsep-konsep tersebut. Salah satu hal yang unik dan perlu mendapat perhatian adalah bahwa materi yang diajarkan kebanyakan bersifat abstrak, oleh karena itu siswa harus mulai mengembangkan imajinasi agar dapat memahami konsep yang mendasar dalam ilmu kimia (Scerri, 2000).

Berdasarkan hasil analisis kebutuhan yang dilakukan terhadap siswa kelas VII SMPN 51 Bekasi yang berjumlah 39 responden, menyatakan bahwa 100\% responden pernah menggunakan komputer dengan interval yang cukup sering (79,92\%). Lebih dari setengah responden $(66,67 \%)$ menyatakan bahwa materi IPA (kimia) kelas VII cukup sulit. Penelitian yang dilakukan Juanda dkk (2007), menyatakan bahwa banyak konsep IPA yang bersifat abstrak dapat ditingkatkan pemahamannya oleh siswa dan guru dengan memanfaatkan multimedia berbantuan komputer (ICT).

Oleh karenanya, diharapkan bahan ajar dalam bentuk CD pembelajaran ini dapat digunakan sebagai bahan ajar pelengkap dalam pembelajaran kimia, guna meningkatkan pemahaman dan minat siswa untuk belajar kimia.

Penelitian ini bertujuan menghasilkan bahan ajar Perubahan Fisika dan Kimia (reaksi kimia) berbasis ICT dalam pembelajaran kimia untuk SMP kelas VII.Selanjutnya dilakukan, Uji kelayakan produk yang dihasilkan (bahan ajar perubahan fisika dan kimia (reaksi kimia)

berbasis ICT dalam bentuk CD pembelajaran).

\section{Metodologi Penelitian}

Penelitian dilakukan di Jurusan Kimia FMIPA UNJ dan uji kelayakannya dilakukan di SMPN 5 Bekasi dan SMP Terpadu Widya Duta Bekasi, selama kurun waktu bulan Januari 2010 Desember 2010.

Subyek penelitian ini adalah siswa kelas IX SMPN 5 Bekasi dan SMP Terpadu Widya Duta Bekasi, masingmasing satu kelas.

Metode penelitian yang dilakukan merupakan metode Penelitian dan Pengembangan (Research and Development), yaitu suatu proses atau langkah-langkah untuk mengembangkan suatu produk baru, atau menyempurnakan produk yang telah ada, yang dapat dipertanggungjawabkan (Sujadi, 2003). Penelitian pengembangan pendidikan diarahkan pada pengembangan produk yang efektif bagi keperluan sekolah yang merupakan penelitian terapan.Penelitian semacam ini lebih mementingkan perubahan yang membawa perbaikan daripada kemengapaannya (why?).

Sasaran utama penelitian pengembangan bukan merumuskan atau mengkaji teori tertentu, melainkan mengembangkan suatu produk tertentu untuk penggunaannya di sekolah (Semiawan, 2007). Prosedur yang dilakukan dalam penelitian ini meliputi (Sujadi, 2003): 
1. Analisis Kebutuhan

Analisis kebutuhan dilakukan melalui survei tentang pembelajaran kimia di SMP dengan responden siswa dan guru.Hasil analisis tersebut dijadikan acuan untuk pengembangan bahan ajar kimia berbasis ICT dalam pembelajaran kimia SMP, sehingga diharapkan bahan ajar yang dihasilkan benar-benar sesuai dengan kebutuhan.

2. Pengembangan Bahan Ajar

Tahap ini diawali dengan studi literatur untuk mendapatkan isi bahan ajar yang dibuat.Selanjutnya dilakukan pembuatan bahan ajar berupa $C D$ interaktif. Bahan ajar dibuat dengan menggunakan fasilitas program macromedia Flash. Bahan ajar dibuat ke dalam slide-slide presentasi yang berisi judul, gambar-gambar dalam reaksi kimia, materi, aplikasi dalam kehidupan, kesimpulan, dan soal-soal. Link yang telah ada kemudian dibuat ke dalam program Flash yang lebih interaktif. Flash berisikan animasi aplikasi reaksi kimia, proses terjadinya reaksi kimia, dan latihan soal yang berisikan evaluasi berupa soal pilihan ganda. Alokasi waktu isi CD pembelajaran ini berkisar antara 15 - 20 menit.

3. Tahap Uji Kelayakan Produk

Tujuan dari tahap uji kelayakan ini adalah untuk memperoleh masukanmasukan tentang produk yang dihasilkan, yang dijadikan dasar untuk memperbaiki bahan ajar.Uji kelayakan dilakukan dengan menggunakan angket yang diberikan kepada ahli materi, praktisi media, guru SMP, dan siswa SMP.

Teknik dan Teknik pengumpulan data yang dilakukan dalam penelitian pengembangan ini, meliputi:

1. Observasi pembelajaran di kelas.

2. Analisis kebutuhan berupa angket siswa dan guru.

3. Kuesioner para ahli (ahli kimia dan ahli media).

4. Kuesioner guru dan siswa terhadap bahan ajar.

Sedangkan instrumen penelitian yang digunakan pada penelitian berdasarkan skala Likert 1 sampai 5 yang kemudian diuji validitasnya menggunakan korelasi product moment dan reliabilitasnya menggunakan Alpha Cronbach.

Hasil uji kelayakan dibuat interpretasi untuk mengetahui apakah bahan ajar yang dibuat sudah sesuai dengan kebutuhan atau tidak.Skala penilaian instrumen berdasarkan skala Likert, disajikan pada tabel 1 (Arikunto, 2002).

\section{Hasil dan Pembahasan}

Hasil analisis kebutuhan menyatakan bahwa $100 \%$ responden pernah menggunakan komputer. Sebanyak $79,92 \%$ rata-rata siswa menggunakan komputer lebih dari dua kali seminggu dan sebanyak $84,62 \%$ siswa telah mengenal $C D$ pembelajaran. 
Tabel 1. Hasil Analisis Uji Kelayakan Materi

\begin{tabular}{|c|l|c|c|c|}
\hline No. & \multicolumn{1}{|c|}{ Indikator } & $\begin{array}{c}\text { Butir } \\
\text { Pertanyaan }\end{array}$ & $\%$ & Interpretasi \\
\hline 1. & $\begin{array}{l}\text { Substansi materi yang disajikan } \\
\text { dalam program interaktif memiliki } \\
\text { relevansi dan kompetensi yang } \\
\text { harus dimiliki siswa }\end{array}$ & 1 dan 2 & 95 & Sangat Baik \\
\hline 2. & Isi & $\begin{array}{c}3,4,5,6, \\
7, \text { dan } 8\end{array}$ & 88,3 & Sangat Baik \\
\hline 3. & $\begin{array}{l}\text { Kesesuaian dengan perkembangan } \\
\text { peserta didik }\end{array}$ & 9 dan 10 & 95 & Sangat Baik \\
\hline
\end{tabular}

Siswa SMPN 5 Bekasi menyatakan pernah menggunakan $C D$ pembelajaran $(64,1 \%)$ dan mereka tertarik dengan CD pembelajaran (66,67\%). Keunggulan CD pembelajaran IPA (kimia) yang telah mereka lihat adalah memudahkan memahami konsep abstrak (40,82\%), animasi dan tampilan menarik (32,65\%), serta materi yang disajikan singkat dan padat $(26,53 \%)$. Dari data tersebut dapat disimpulkan bahwa siswa tertarik dengan media $\quad C D$ pembelajaran dengan keunggulan-keunggulan yang mereka ketahui sebelumnya.

Lebih dari setengah siswa SMPN 5 Bekasi menyatakan bahwa materi IPA (kimia) kelas VII cukup sulit (66,67\%) dan penyebabnya adalah kurangnya motivasi untuk belajar kimia (48,98\%). Hal ini dapat disebabkan oleh kurangnya media pembelajaran $(27,66 \%)$ dan sedikit yang berpendapat bahwa penyajian materi yang monoton (14,89\%). Dari hasil tersebut dapat dinyatakan bahwa diperlukan media pembelajaran tambahan sebagai pelengkap guna memotivasi siswa dalam belajar kimia, yang dirasa oleh mereka pelajaran yang cukup sulit.

Berkaitan dengan rencana pengembangan bahan ajar berbasis ICT untuk menunjang pelaksanaan kegiatan belajar mengajar IPA kimia SMP, hampir seluruh siswa mendukung (92,31\%). Harapan siswa mengenai bahan ajar yang akan dikembangkan adalah adanya interaksi dengan peserta didik (37,93\%) dan berisi uraian materi yang bersifat singkat, jelas, dan padat $(31,04 \%)$.

Kesimpulan yang dapat diambil adalah siswa mendukung rencana pengembangan bahan ajar berbasis ICT dalam bentuk CD pembelajaran. Harapan siswa terhadap $C D$ pembelajaran yang akan dikembangkan yaitu, berisi uraian materi singkat, jelas, dan padat, serta siswa dapat berinteraksi dengan bahan ajar.

Hasil wawancara dengan guru IPA SMPN 5 Bekasi diperoleh hasil bahwa responden telah lama mengajar Sains/IPA terutama Fisika di SMP yaitu sekitar 28 tahun.Selama mengajar, banyak metode yang telah diterapkan mulai dari ceramah hingga demonstrasi.Secara keseluruhan tidak ada materi IPA SMP yang memerlukan penanganan khusus, hanya saja kesulitan yang dihadapi dalam pembelajaran kimia yaitu, dalam menyampaikan materi kimia yang dirasa baru oleh siswa kelas VII.

Sejak tahun 2008 SMPN 5 Bekasi menjadi Sekolah Rintisan Bertaraf Internasional (RSBI).Fasilitas yang disediakan SMPN 5 Bekasi untuk 
menunjang kegiatan belajar mengajar IPA cukup lengkap, seperti laboratorium dan alat-alat laboratorium.Responden juga cukup sering untuk melakukan demonstrasi atau praktikum di laboratorium dalam mengajarkan pelajaran IPA.

Fasilitas komputer, laptop, dan LCD cukup memadai dengan jumlah komputer sebanyak 30 buah dan LCD terpasang di setiap kelas.

Responden juga telah mengenal software/CD pembelajaran dan pernah menggunakannya. Reponden menyatakan bahwa $C D$ pembelajaran sangat membantu guru dan siswa dalam proses pembelajaran. Responden juga mendukung mengenai rencana pengembangan bahan ajar berbasis ICT.

Berdasarkan data-data tersebut, diperlukan suatu bahan ajar untuk memudahkan pembelajaran IPA (kimia) baik untuk guru maupun untuk siswa. Bahan ajar akan dibuat dalam bentuk CD pembelajaran yang akan digunakan di kelas. Oleh karenanya diperlukan mengembangkan bahan ajar IPA (kimia) berbasis ICT yang diharapkan dapat Kemudian mengembangkan bahan ajar dengan menggunakan berbagai literatur baik melalui buku teks maupun pencarian melalui internet. Adapun isi CD pembelajaran yang dikembangkan, berisi pengertian, konsep, soal review, ilustrasi gambar pendukung, animasi reaksi kimia, dan evaluasi berupa soal pilihan ganda berikut dengan penjelasannya.

\section{a. Uji Kelayakan Materi}

Uji kelayakan materi bertujuan untuk menguji kelayakan CD pembelajaran yang telah dibuat dari segi materi.Hasil analisis materi dijadikan sebagai masukkan untuk perbaikan produk.Uji kelayakan materi dilakukan oleh dua orang pengkaji yang merupakan dosen kimia FMIPA UNJ.

Dari tabel di atas dapat dilihat bahwa $C D$ pembelajaran yang dikembangkan memiliki relevansi dan standar kompetensi yang harus dikuasai siswa (95\%), CD pembelajaran juga telah sesuai dengan perkembangan peserta didik (95\%), dan isi CD pembelajaran telah sesuai dari segi konsep materi $(88,3 \%)$.

Berdasarkan data yang telah diuraikan dapat diambil kesimpulan bahwa bahan ajar perubahan fisika dan kimia yang dikembangkan dapat digunakan sebagai pelengkap dalam pembelajaran IPA (kimia) di SMP.

Tabel 2. Hasil Analisis Uji kelayakan Media

\begin{tabular}{|c|l|c|c|c|}
\hline No. & \multicolumn{1}{|c|}{ Indikator } & Butir Pertanyaan & $\%$ & Interpretasi \\
\hline 1. & Struktur dan navigasi & $5,6,7$, dan 8 & 80 & Baik \\
\hline 2. & Desain visual & $1,2,3$, dan 4 & 85 & Sangat Baik \\
\hline
\end{tabular}


Tabel 3. Hasil Analisis Uji Kelayakan Oleh Guru

\begin{tabular}{|c|l|c|c|c|}
\hline No. & \multicolumn{1}{|c|}{ Indikator } & Butir Pertanyaan & $\%$ & Interpretasi \\
\hline 1. & $\begin{array}{l}\text { Relevansi materi dengan } \\
\text { kompetensi }\end{array}$ & 90 & Sangat Baik \\
\hline 2. & Sajian menarik & 4 dan 5 & 90 & Sangat Baik \\
\hline 3. & Isi & $2,3,6,7$, dan & 94 & Sangat Baik \\
\hline 4. & Sistem navigasi & 8 dan 9 & 95 & Sangat Baik \\
\hline 5. & Desain visual & $\begin{array}{c}11,13,14, \\
\text { dan } 15\end{array}$ & 86 & Sangat Baik \\
\hline
\end{tabular}

\section{b. Uji Kelayakan Media}

Uji kelayakan media dilakukan oleh dosen UNJ sebanyak dua orang, dengan rincian dosen kimia FMIPA UNJ satu orang dan dosen seni rupa FBS UNJ satu orang.Tujuan uji kelayakan ini adalah untuk mengetahui menarik atau tidaknya media tersebut serta menguji kelayakan bahan ajar dari segi tampilan.Hasil uji kelayakan media terdapat pada tabel 2 .

Berdasarkan data di atas diketahui bahwa persentase desain visual sebesar $85 \%$ yang menginterpretasikan bahwa desain visual telah sangat baik, dan untuk struktur dan navigasi pun mendapat persentase sebesar $80 \%$ yang menandakan struktur dan navigasi pada CD pembelajaran sudah baik. Komentar dan saran-saran yang diperoleh dari pengkaji media adalah untuk tampilan lay out menu utama sudah baik, warnawarna yang dipilih senada dan mewakilkan keceriaan, warna background sudah sesuai, untuk tombol-tombol yang akan di klik sebaiknya menggunakan warna background yang berbeda atau diberi button agar dapat dibedakan dan memudahkan siswa dalam meng-klik. Navigasi sudah cukup baik dan lay out dapat dikatakan baik, hanya beberapa elemen saja yang agak menggangu dan banyak menggunakan warna.

\section{c. Uji Kelayakan Oleh Guru}

Uji kelayakan pada tahap ini untuk mengetahui pendapat guru mengenai bahan ajar yang dikembangkan dalam bentuk $C D$ pembelajaran.Uji kelayakan dilakukan pada dua responden guru IPA (mengajar fisika dan kimia), yaitu guru kelas 7 SMPN 5 Bekasi dan SMP Terpadu Widya Duta.Hasil analisis uji kelayakan $C D$ pembelajaran oleh guru dapat dilihat pada tabel 3 .

Berdasarkan data tersebut dapat diketahui bahwa persentase sistem navigasi memperoleh nilai tertinggi dengan nilai 95\%, yang menandakan bahwa sistem navigasi dapat digunakan dengan mudah dan tidak membuat bingung pengguna.CD pembelajaran telah berisi materi yang jelas dan memiliki urutan yang sangat baik (94\%).Relevansi materi dengan kompetensi sangat baik dan sajian materi dalam CD pembelajaran menarik (90\%).Desain visual yang disajikan jelas dan susuai dengan materi (86\%).Adapun masukan yang terima adalah penulisan huruf yang perlu diperbesar dan agar produk yang dikembangkan dapat disebarluaskan dan disosialisasikan. 
Tabel 4. Hasil Analisis Uji Kelayakan Siswa Kelompok Kecil

\begin{tabular}{|c|l|c|c|c|}
\hline No. & \multicolumn{1}{|c|}{ Indikator } & Butir Pertanyaan & $\%$ & Interpretasi \\
\hline 1. & Sajian menarik & 3,4, dan 13 & 79,3 & Baik \\
\hline 2. & Isi media & $1,2,5$, dan 6 & 92 & Sangat Baik \\
\hline 3. & Sistem navigasi & 7,8, dan 10 & 83 & Sangat Baik \\
\hline 4. & Desain visual & 9,11, dan 12 & 76,3 & Baik \\
\hline
\end{tabular}

Berdasarkan deskripsi tersebut, dapat diketahui bahwa materi dalam bahan ajar yang dikembangkan sesuai dengan kompetensi yang harus dikuasai siswa.

Sistem navigasi dalam pengoperasian mudah digunakan, media bahan ajar atau desain visual menarik untuk dilihat, dan isi sudah sesuai dengan kompetensi dasar materi.Maka, dapat disimpulkan bahwa pengembangan media bahan ajar perubahan fisika dan kimia dapat atau layak digunakan sebagai bahan ajar pelengkap dalam pembelajaran IPA (kimia) di SMP.

\section{d. Uji Coba Kelompok Kecil}

Uji coba oleh siswa bertujuan untuk mengetahui pendapat siswa mengenai bahan ajar yang dikembangkan dalam bentuk $C D$ pembelajaran.Uji coba kelompok kecil ini dilakukan pada siswa kelas 9 SMPN 5 Bekasi dan SMP Terpadu Widya Duta Bekasi.Kelompok kecil diperoleh dengan mengambil sampel 10 siswa SMPN 5 Bekasi dan 10 siswa SMP Terpadu Widya Duta.

Tujuan pengambilan data uji coba kelompok kecil adalah untuk mengetahui hasil sementara guna mempermudah perhitungan sebagai gambaran awal mengenai sikap siswa terhadap bahan ajar yang akan di kembangkan dan perbaikan dini sebelum di uji pada kelompok besar.

Berdasarkan hasil uji coba kelompok kecil, nilai persentase isi media sebesar $92 \%$, hal tersebut menunjukan bahwa isi media terinterpretasikan pada kategori sangat baik.Sistem navigasi media mudah untuk dioperasikan (83\%). Sajian dalam CD pembelajaran sudah baik $(79,3 \%)$ dan desain visual memperoleh angka 76,3\% dengan interpretasi yang juga baik. Saran-saran yang diperoleh dari siswa adalah warna yang digunakan lebih banyak lagi dan gambar-gambar perlu diperbanyak.

Berdasarkan uraian hasil uji kelayakan oleh siswa kelompok kecil dapat disimpulkan CD pembelajaran yang dikembangkan telah sesuai dari segi isi maupun desain tampilan. Sehingga dapat membantu siswa dalam memahami materi perubahan fisika dan kimia (reaksi kimia).

\section{e. Uji Coba Kelompok Besar}

Uji coba kelompok besar dilakukan pada 26 siswa SMPN 5 Bekasi dan 26 siswa SMP Terpadu Widya Duta dengan total sebanyak 52 siswa.Hasil uji kelayakan oleh siswa kelompok besar terdapat pada tabel 5 . 
Tabel 5. Uji Kelayakan Siswa Kelompok Besar

\begin{tabular}{|c|l|c|l|l|}
\hline No. & \multicolumn{1}{|c|}{ Indikator } & Butir Pertanyaan & $\%$ & Interpretasi \\
\hline 1. & Sajian menarik & 3, 4, dan 13 & 81,7 & Sangat Baik \\
\hline 2. & Isi media & $1,2,5$, dan 6 & 89,5 & Sangat Baik \\
\hline 3. & Sistem navigasi & 7,8, dan 10 & 81,3 & Sangat Baik \\
\hline 4. & Desain visual & 9,11, dan 12 & 80,8 & Sangat Baik \\
\hline
\end{tabular}

Dari hasil tersebut dapat dikatakan bahwa persentase isi media masih menduduki peringkat pertama dalam nilai persentase yaitu sebesar $89,5 \%$. Sistem navigasi memperoleh persentase sebesar $81,3 \%$ dengan interpretasi sangat baik. Hal ini menandakan bahwa sistem navigasi pada media mudah digunakan atau dioperasikan. Pada indikator desain visual persentase yang hasilkan sebesar $80,8 \%$, hal tersebut menunjukan bahwa desain media layak untuk ditampilkan. Nilai persentase indikator sajian menarik adalah sebesar $81,7 \%$ dengan interpretasi baik, dengan kata lain sajian dalam media sudah menarik untuk ditampilkan sebagai bahan ajar pelengkap pembelajaran materi perubahan fisika dan kimia (reaksi kimia). Adapun saran-saran yang diberikan siswa mengenai bahan ajar CD pembelajaran adalah sebagai berikut: (1) animasi perlu diperbanyak, (2) karakter tulisan dibuat semenarik mungkin, dan (3) warna-warna yang digunakan lebih meriah.

Berdasarkan uraian hasil uji coba kelompok besar, dapat disimpulkan bahwa semua interpretasi setiap indikator sudah sangat baik.

Maka, dapat disimpulkan bahwa bahan ajar perubahan fisika dan kimia yang dikembangkan layak dan dapat digunakan sebagai pelengkap dalam pembelajaran IPA (kimia) di SMP.

\section{Kesimpulan dan Saran}

Berdasarkan hasil penelitian yang telah dilakukan, dapat diambil kesimpulan bahwa:

1. Penelitian ini telah berhasil mengembangkan bahan ajar dalam bentuk $C D$ pembelajaran untuk materi perubahan fisika dan kimia (reaksi kimia).

2. Berdasarkan hasil uji kelayakan bahan ajar oleh ahli materi, media dan guru serta hasil uji coba kepada siswa kelompok kecil dan besar, bahan ajar yang dikembangkan dalam bentuk $C D$ pembelajaran

menggunakan macromedia flash layak digunakan sebagai bahan ajar pelengkap bahan ajar dalam pembelajaran IPA (kimia) Kelas VII di SMP. 


\section{DAFTAR PUSTAKA}

Abdullah, N. F. 2010. Mewujudkan Pembelajaran Berbasis ICT. http://forantum.blogspot.com/2010/01/mewujudkan-pembelajaran-berbasis-ict.html, $\quad 30$ Desember 2010, pukul 20.12 WIB.

Abidin, M. Z. 2010.Konsep dan Pentingnya Penelitian dan Pengembangan.http://meetabied.wordpress.com/2010/03/20/penelitian-danpengembangan/, 23 Agustus 2010, pukul 22.05 WIB.

Adimphrana, K. 2008. Makalah Strategi Pengembangan Pembelajaran Berbasis TIK. http://kwarta.wordpress.com/2008/08/25/strategi-pengembangan-pembelajaran-berbasistikJ, 30 Desember 2010, pukul 20.50 WIB.

Arikunto, S. 2002. Dasar-Dasar Evaluasi Pendidikan (Edisi Revisi). Jakarta: PT. Bumi Aksara. Cet. Ke-3.

Arsyad, A. 2007.Media Pembelajaran. Jakarta: PT Rajagrafinda Persada.

Hanckey.2006. Pengembangan Bahan Ajar.http://www.hanckey.pbwiki.com/f/Sisteminformasi-untuk-Pendidikan-(8).pptosn.web.id/Data/Presentasi/BAHAN-AJAR/BahanAjar.ppt, 14 September 2009, pukul 09.25 WIB.

Juanda, E. A., Liliasari, dan Suhandi, A. 2007. Implementasi ICT Based Lesson Study Dalam Pembelajaran Sains Untuk Membangun Learning Community Bagi Guru IPA SMP Dalam Rangka Meningkatkan Kualitas Pendidikan Dasar Di Jawa Barat. http://file.upi.edu/Direktori/E-

FPTK/JUR.PEND.TEKNIKELEKTRO/195508261981011ENJANGAHMADJUANDA/Artikel SeminarInternasionalLSICT_REV.pdf, 23 Agustus 2010, pukul 21.10 WIB.

Munir.2001. Aplikasi Teknologi Multimedia Dalam Proses Belajar Mengajar, Mimbar Pendidikan. Bandung: University Press UPI.

Munir.2008. Kurikulum Berbasis Teknologi Informasi dan Komunikasi. Bandung: Alfabeta. Muslim. 2007. Teknologi Informasi Dalam Pendidikan. http://www.linkpdf.com/download/dl/teknologi-informasi-dalam-globalisasi-pendidikan-.pdf, 23 Agustus 2010, pukul 20.02 WIB.

Nurbaity. 2004. Evaluasi Pengajaran. Jakarta: FMIPA UNJ.

Sadiman, A. S. 2002. Media Pendidikan: Pengertian Pengembangan dan Pemanfaatannya. Jakarta: PT Raja Grafindo Persada.

Scerri, E. R. 2000. Philosophy of Chemistry-A New Interdisciplinary Field?.Journal of $\begin{array}{lllll}\text { Chemical } & \text { Education, } & \text { Vol. } & \text { No. }\end{array}$ http://www.chem.ucla.edu/dept/Faculty/scerri/pdf/p.o.c._JCE.pdf_1.pdf, 10 Januari 2010, pukul 03.15 WIB.

Semiawan, C. R. 2007. Catatan Kecil Tentang Penelitian dan Pengembangan IImu Pengetahuan. Jakarta: Kencana prenada Media group. Cet I. 
Sidik, I. D. 2001.Menuju Masyarakat Belajar; Menggagas Paradigma Baru Pendidikan. Jakarta: Logos Wacana IImu.

Sudijono, A. 2001.Pengantar Evaluasi Pendidikan. Jakarta: PT. Raja Grafindo Persada.

Sujadi. 2003. Metodologi Penelitian Pendidikan. Jakarta. Rineka Cipta.

Sukmadinata, N. S. 2006. Metode Penelitian Pendidikan. Bandung: Remaja Rosdakarya.

Syukri. 1999. Kimia Dasar 1. Bandung: Penerbit ITB.

Wasis, Sukarmin, Sudibyo, E., Azizah U., dan Kuswanto, H. 2008. Contextual Teaching and Learning IImu Pengetahuan Alam. Jakarta: Pusat Perbukuan Departemen Pendidikan Nasional. 